\title{
EL CINE MÁS ALLÁ DEL SIGNO: REVISITANDO EL CONCEPTO DE INDEXICALIDAD EN LA TEORÍA DE ANDRÉ BAZIN
}

\author{
CINEMA BEYOND SIGNS: REVISITING INDEXICALITY \\ IN ANDRÉ BAZIN'S FILM THEORY
}

\author{
Lourdes ESQUEDA VERANO \\ Universidad de Navarra \\ lesqueda@unav.es
}

Resumen: Las recientes transformaciones tecnológicas del cine han reavivado el debate sobre las propiedades de la imagen fotográfica, consolidando la teoría cinematográfica de André Bazin como lectura obligatoria. En especial, cabe destacar su texto sobre "La ontología de la imagen fotográfica", donde Bazin establece una relación entre la materialidad del cine y su tendencia estética hacia el realismo. Este artículo ofrece una clarificación terminológica sobre uno de los conceptos más fundamentales de este texto - la huella de luz — que suele identificarse con la noción de signo indexical propuesta por C. S. Peirce, propiciando consideraciones semióticas en una teoría del cine completamente ajena a la misma.

Palabras clave: Imagen fotográfica. Teoría del cine. Indexicalidad. Realismo. André Bazin. 


\begin{abstract}
The recent technological transformations of cinema have brought back the debate on the properties of the photographic image, calling attention once again to André Bazin's film theory, especially his key work "The Ontology of the Photographic Image." In this text, Bazin establishes a correlation between the materiality of the cinema and its aesthetic tendency towards realism. This article offers a terminological clarification on one of the most fundamental concepts of his theory the trace-, which is frequently identified with C.S. Peirce's indexicality, prompting semiotic readings of a pre-semiotic film theory.
\end{abstract}

Key Words: Photographic Image. Film Theory. Indexicality. Realism. André Bazin.

\title{
1. INTRODUCCIÓN
}

Hace más de medio siglo que André Bazin escribió su conocida teoría del cine. Se recurre a ella, habitualmente, para reflexionar sobre la materialidad del medio, en especial cuando surge una innovación tecnológica en el mismo. Así, a partir del advenimiento del soporte digital y de la creciente hibridación de la imagen cinematográfica, la teoría de Bazin ha mostrado su vigencia y actualidad en el diálogo sobre las grandes preguntas que surgen en lo relativo a las propiedades básicas y fundamentales de las imágenes de registro — sean fotográficas o cinematográficas - Mucho se ha escrito sobre el texto de apertura seleccionado por Bazin para Qu'est-ce que le cinéma?, "Ontologie de l'image photographique" (en adelante, "Ontologie"). La lectura de este texto, central en la reflexión sobre el realismo propio del cine, se encuentra condicionada por la clasificación de las teorías cinematográficas realizada por Peter Wollen. En Signs and Meaning of Cinema, Wollen describe el realismo baziniano como una consecuencia del carácter indexical de 
sus imágenes. La identificación entre el concepto de indexicalidad y la comprensión baziniana de la ontología de la imagen fotográfica es tal en la academia que incluso llegan a utilizarse como sinónimos. Como hacen notar Martin Lefebvre y Martin Furstenau, que los estudios de cine tiendan a esta homologación se debe a que "la indexicalidad era entendida frecuentemente como una variación meramente semiótica de la pretensión ontológica en Bazin" (2002: 94). En realidad, aunque la indexicalidad - entendida como una conexión dinámica entre el modelo y su imagen fotográfica - puede ayudar efectivamente a dar cuenta de algunas de las características de la ontología de la imagen de registro, la reducción de sus cualidades a este término semiótico empobrece sus potencialidades documentales y artísticas, y lleva la reflexión teórica de cine a un callejón sin salida, donde o se opta por asumir esta identificación como verdadera, o se niega la utilidad y vigencia de la teoría baziniana. Con el objetivo de facilitar el acceso del lector a la riqueza de este texto esencial de la teoría cinematográfica, el presente trabajo rescata el término huella utilizado por Bazin para designar esta realidad. Como se verá a lo largo de las siguientes páginas, la huella baziniana actúa de un modo más similar a la percepción cotidiana de los objetos del mundo sensible que a la manera del índice peirceano.

Este artículo se divide en tres partes. En el primer epígrafe se analizan las principales consecuencias de aproximarse a Bazin desde un enfoque puramente semiótico o desde planteamientos afines, como son los de Barthes y Sontag, y el tipo de errores a los que puede conducir al lector. El segundo epígrafe ofrece una comparación entre el concepto peirceano de índice y la huella de luz descrita por Bazin. Aquí se repasará tanto el índice puro como los degenerados con el objetivo de encontrar los rasgos compartidos entre todos ellos y valorar, así, el alcance de la semiótica en la teoría baziniana. Finalmente, la caracterización de la huella en sí es el cometido del último epígrafe. Allí definimos la huella atendiendo a los tres aspectos que, según defiende Bazin en "Ontologie", la configuran: el carácter automático de su producción; la relación que la imagen 
fotográfica guarda respecto al referente que la origina; y, por último, el efecto psicológico de estas imágenes de registro en el espectador. Estos tres rasgos aportan luz sobre por qué Bazin considera que, en virtud de su materia prima, el cine es un arte de tendencia esencialmente realista.

\section{EL CONTEXTO SEMIÓTICO DE LA COMPRENSIÓN PEIRCIANA DE BAZIN: BARTHES, SONTAG}

Antes de abordar la indexicalidad de la imagen fotográfica en la teoría de André Bazin, es necesario advertir que en sus casi 2.600 artículos publicados, Bazin nunca utilizó dicho término. Sin embargo, la teoría baziniana se encuentra tradicionalmente unida al mismo. El principal motivo de esta identificación tiene que ver con la necesidad de distinguir entre la pintura y la fotografía, ya que, a diferencia de la primera, esta última participa, en palabras de Bazin, "de la existencia del modelo como huella digital" (1966: 19). Es decir, la génesis de la imagen fotográfica es causal, no proviene de la imaginación del artista. Y la causalidad es el atributo que distingue la relación entre el referente y el signo indexical en la teoría peirceana. Sin embargo, Bazin no planteó su teoría a partir de términos semióticos, sino que utilizó una serie de términos que se asemejan a lo que C. S. Peirce denominó como indexical: huella, rastro, impresión, máscara, molde, etc. Debido a la distancia entre un planteamiento semiótico y uno fenomenológico, como es el caso de Bazin, la coincidencia terminológica no justifica la equiparación entre ambas perspectivas. Como se verá a continuación, el recurso a términos semióticos acarrea una serie de implicaciones que es necesario explicitar, con el objetivo de alcanzar una comprensión depurada de la ontología de la imagen de registro a la que hace referencia Bazin.

Como ya se ha apuntado, la importación del término indexicalidad a la teoría baziniana data del año $1969^{1}$, cuando, en Signs and Meaning in

\footnotetext{
${ }^{1}$ Previamente ya se habían publicado estudios específicos que vinculaban la semiótica y la fotografía, como es el caso de Roland Barthes, quien hablaba de la fotografía como de "un
} 
the Cinema, Peter Wollen realiza una clasificación de corte estructuralista sobre las principales teorías cinematográficas. Wollen, siguiendo a Roman Jakobson, identifica cada tipo de signo propuesto por Peirce en su tricotomía -índice, icono, símbolo - con un teórico cinematográfico que lo representa de forma paradigmática en su comprensión del cine. Wollen relaciona a Christian Metz con la dimensión simbólica (el cine como código y lenguaje); a Josef Von Sternberg con la icónica (la iluminación desde el punto de vista de las artes plásticas); y a Bazin con la dimensión indexical (donde encontramos un vínculo existencial entre el modelo y su representación) (1970: 136).

No obstante, más allá del trabajo de Wollen, resultan más influyentes en este contexto en La Chambre claire y On Photography, conocidas obras de Roland Barthes y Susan Sontag respectivamente. Aunque ninguno de los dos autores — seguidores más bien de premisas estructuralistas - se declaran deudores del pensamiento de Bazin, en ambos libros es evidente una marcada influencia baziniana tanto en su enfoque al distinguir entre la imagen fotográfica y otras imágenes como en el recurso a determinados términos ${ }^{2}$. Bazin, Sontag y Barthes coinciden en apuntar que la imagen fotográfica es esencialmente distinta de otras imágenes debido a la conexión causal entre la realidad y la imagen que percibimos en la fotografía. Lo exclusivo de la fotografía, según Barthes, radica en que "para que exista la imagen, es necesario que la cosa haya estado allí" (1994: 136); en la misma línea, que "el lenguaje es ficcional por naturaleza; [...] mientras que la fotografía es indiferente a todo añadido: no inventa nada" (1994: 150). Por su parte, Sontag menciona que "el registro fotográfico confirma que el modelo existe" (1978: 175).

mensaje sin código" en "Le message photographique" (1961: 128) o en su "Éléments de sémiologie" (1964b). Cabe destacar también el estudio de Umberto Eco, donde se refiere a los mensajes visuales, como el cine o la publicidad, La estructura ausente (1968).

${ }^{2}$ Aunque Barthes escribió otros textos específicos sobre la fotografía — como "Réthorique de l'image" (1964a) - , es en La Chambre claire (1994) donde resalta una transición intelectual de Barthes de la filmología de Gilbert Cohen-Séat y un enfoque semióticosaussureano a una perspectiva más personal y descriptiva-científica. 
También es reseñable el gran parecido entre el modo en que estos autores expresan asuntos relativos a la temporalidad y a la génesis automática de la fotografía. Para todos ellos, la fotografía aparece como una victoria sobre la muerte. Bazin habla de embalsamar el tiempo mediante la fotografía para sustraerlo de su propia corrupción (1966: 19). Sontag dice que "una vez concluido el acontecimiento, la fotografía aún existirá, confiriéndole una especie de inmortalidad" (1978: 21) a esa realidad preservada. Del mismo modo Barthes, quien escribe La Chambre claire en parte para superar la muerte de su madre y comprender el modo en que se aferra a su recuerdo a través de una fotografía en concreto, explica que la fotografía nos hace vivir una micro experiencia de la muerte porque nos convierte en un sujeto que deviene objeto tras ser fotografiado, logrando la inmortalidad a través de su propia imagen (1994: 46).

Es igualmente significativa la coincidencia en determinadas metáforas que describen el funcionamiento de la imagen de registro. Para Sontag, la fotografía no es solo una imagen, como la pintura, sino "un vestigio, un rastro directo de lo real, como una huella o una máscara mortuoria" (1978: 164). Esta última frase parece una referencia directa a una de las notas al pie de "Ontologie", donde Bazin vincula el automatismo en la producción de la fotografía con las mascarillas mortuorias y explica la génesis de la imagen fotográfica como una huella hecha por la luz (1966: 17). Respecto a esto último, Barthes dice que, debido a su base fotoquímica, "la fotografía es literalmente una emanación del referente" (1994: 142), porque los rayos de luz se impresionan en el negativo.

Todas estas referencias más o menos explícitas al ensayo de Bazin sobre la ontología de la imagen fotográfica nos permiten establecer un vínculo sistemático — sugerente, cuando menos - entre estos autores ${ }^{3}$. Sin embargo, no debemos menospreciar las diferencias entre la perspectiva baziniana y el enfoque de Sontag y Barthes. Es, precisamente, en estas

\footnotetext{
${ }^{3} \mathrm{Al}$ tiempo que confirman lo que Hervé Joubert-Laurencin llama el borramiento de Bazin de la escena intelectual francesa en los 60 y 80, ya que Barthes obvia que sus textos son habitualmente contestaciones a los escritos bazinianos (cf. Watts, 2016: 38, 40-43).
} 
diferencias donde puede apreciarse con más claridad que el carácter indexical de la imagen fotográfica no da cuenta cabal del sentido en que Bazin comprendía su ontología.

Tanto Sontag como Barthes abordan la imagen fotográfica desde un punto de vista que se debate entre el constructo y la transcripción objetiva (por automática) de la realidad, es decir, comprenden la imagen fotográfica como un signo o sustituto de la realidad; algo que, si bien está ligado a la misma, la reemplaza o la duplica. Mientras Bazin, ajeno a los planteamientos semióticos y psicoanalíticos, la considera re-presentación de una realidad pasada. Así, mientras para Bazin las fotografías nos permiten acceder a la realidad, Sontag entiende que las fotografías “por sí solas son incapaces de explicar nada, son inagotables invitaciones a la deducción, la especulación y la fantasía" (1978: 33). Se trata de una desconfianza cognoscitiva que la lleva a sospechar del realismo fotográfico ${ }^{4}$, como cuando critica "la dudosa reputación [de la fotografía] de ser la más realista, y por ende la más accesible, de las artes miméticas" (1978: 61); e incluso la conduce a dudar sobre la existencia de la realidad misma:

La fotografía implica un acceso instantáneo a lo real. Pero los resultados de esta práctica de acceso instantáneo son otra manera de crear distancia... Poseer el mundo en forma de imágenes es, precisamente, volver a experimentar la irrealidad y lejanía de lo real (1978: 174; énfasis mío).

En una línea similar, el planteamiento constructivista de Barthes impide contemplar la fotografía como evidencia probatoria de una realidad exterior a la propia imagen. Donde Bazin encuentra un punto de acceso, Barthes se topa con un pacto de lectura. Por ello, Barthes sostiene que la

${ }^{4}$ Este realismo fotográfico no es estilístico, sino ontológico. Como lo expresa Jesús González Requena, "frente al realismo de lo verosímil — que es el del realismo discursivo-, la fotografía, y tras ella el cinematógrafo, realizan el proyecto naturalista de un realismo radical: un realismo de lo real que da todo su sentido a la intuición que latía en el pensamiento de Bazin cuando afirmaba que la fotografía es ontológicamente realista" (2013). 
cultura "es un contrato firmado entre creadores y consumidores" (1994: 67). Barthes, también comprende la fotografía como alucinación o distorsión de la realidad y explica que, a pesar de remitir a un momento real del pasado, la fotografía es "falsa a nivel de la percepción" (1994: 194), porque la subjetividad que la percibe puede no reconocerla como verdadera, como le ocurrió a Barthes con las fotografías de su madre fallecida: la reconocía, pero no lograba reencontrarla (1994: 119).

Esta diferencia de enfoques es clara cuando comprobamos que Sontag y Barthes distinguen entre lo real y la realidad (subjetiva o, cuando menos, percibida), mientras que Bazin refiere, sin distinciones, a una única realidad que, precisamente por ser accesible mediante la percepción, es accesible a través de su imagen fotográfica ${ }^{5}$. Por ello, Bazin sostiene que "la fotografía obra sobre nosotros como fenómeno 'natural', como una flor o un copo de nieve en donde la belleza es inseparable del origen vegetal o telúrico" (1966: 18)6. Para Bazin, la fotografía, que restituye una realidad pasada, se une a la creación como fenómeno natural y nos afecta como tal (1966:19). La imagen fotográfica y cinematográfica no es, para Bazin, una copia más sofisticada ni una simple duplicación, sino una nueva forma de remitir a lo real en su ambivalente aparecer (Lebedev, 2016: 190), una suerte de "nueva mirada" con un soporte distinto y propio. Constatamos así que los puntos de encuentro entre Sontag, Barthes y Bazin no implican

\footnotetext{
${ }^{5}$ Aunque Bazin distingue intuitivamente entre un fenómeno y su noúmeno, lo hace más en términos de abstracción y acceso a las esencias o realidades espirituales que a propósito de una actitud de impotencia para acceder a lo real, como ocurre en otros autores. Quitar al referente de la ecuación referente-significante-significado para enfocar el estudio de los fenómenos desde un punto de vista relativo al sujeto equivaldría, en la epistemología baziniana, a negar toda posibilidad cognoscitiva y, por tanto, cualquier relevancia real de la imagen fotográfica en términos de acceso al mundo.

${ }^{6}$ En la compilación de textos para Qu'est-ce que le cinéma?, el término natural aparece entrecomillado (1958: 15), en lugar de en cursivas, como hace Bazin en su texto original: "Elle agit sur nous en temps que phénomène naturel, comme une fleur ou un cristal de neige dont la beauté est inséparable de leur origine végétale ou tellurique" (1947: 408). El entrecomillado pudo haber dado un sentido distinto al buscado por el autor, ya que al aparecer entre comillas el término natural este podría cobrar un sentido metafórico, en lugar de enfático.
} 
una concordancia total entre los primeros y el segundo. Es por ello que no deja de sorprender cómo algunos académicos, como Peter Geimer, llegan a englobar a Peirce, Bazin, Barthes, Krauss, Sontag y Dubois en un grupo homogéneo con el denominador común de la causalidad (2007: 10). Este tipo de agrupaciones bajo un rasgo común tienden a obviar una serie de matices que a su vez delatan diferencias más o menos relevantes entre una teoría y otra: esto es lo que ocurre frecuentemente con la teoría de Bazin, cuando se absolutiza el sentido "genético" de la indexicalidad, en lugar de mirarlo como un origen dirigido sin embargo a una forma nueva de realismo. Como es de esperar, la indexicalidad tampoco agota el planteamiento sontaguiano ni el de Barthes. Suscribimos, pues, el diagnóstico de Stephen Rifkin, quien critica una lectura ya estándar en los estudios de cine donde:

[i]ndexicalidad es usado casi siempre para describir un atributo identificable y esencial al medio de toda representación analógica, sea fotográfica o cinematográfica. Esta característica es el resultado de un proceso tecnológico específico, uno que le otorga a las representaciones una relación privilegiada con la realidad (Rifkin, 2012: 85)

Dicha asimilación entre la indexicalidad y la ontología baziniana, apunta Rifkin, es una reducción que se ha establecido en la academia, dando por buena una confusión simplista a teorías tan diversas como complejas.

A propósito de Bazin, es claro que él no pensaba la fotografía en términos semióticos; así como Peirce no consideraba la fotografía como un ejemplo destacado de la indexicalidad. Mary Ann Doane defiende que la fotografía no debería ser considerada como un índice ejemplar, porque "para Peirce, que definió el signo indexical, la fotografía no era en absoluto el ejemplo más importante. En su descripción, el índice se vacía de contenido; es un signo hueco. Designa algo sin describirlo; su 
función se limita a asegurar una existencia" (2012: 338). Sin embargo, como se expone a continuación, sí hay algunos rasgos compartidos entre la indexicalidad y la ontología de la imagen fotográfica según Bazin. Es relevante, por tanto, realizar una comparación pormenorizada donde se explicitan los puntos de unión y desencuentro entre el índice y la huella, para alcanzar una comprensión cabal del papel que desempeñan este tipo de imágenes en la teoría baziniana.

\section{COMPARACIÓN ENTRE EL ÍNDICE PEIRCEANO Y LA HUELLA BAZINIANA}

Aunque la noción de huella de luz descrita por Bazin no nace con una orientación semiótica ni se trata de un término equivalente al de indexicalidad, existe un rasgo genético en la imagen de registro - fotográfica o cinematográfica - que permite establecer un puente entre un enfoque semiótico y uno ontológico al abordar el estudio de dichas imágenes. En concreto, el punto común entre el índice y la huella se encuentra en su origen causal y en la relación dinámica que dicha imagen establece respecto a la realidad y al sujeto que la percibe.

\subsection{La conexión dinámica como elemento común entre la huella y el índice}

Veamos más detenidamente este punto de encuentro a partir de la definición de índice aportada por Peirce:

[El índice es] un signo o representación que se refiere a su objeto no tanto a causa de alguna similitud o analogía con él, ni tampoco a causa de que esté asociado con caracteres generales que de hecho ese objeto posee, sino porque está en conexión dinámica (incluida una conexión espacial) tanto con el objeto individual, por una parte, como con los sentidos o memoria de la 
persona para la que funciona como signo, por otra parte (1994: 2.305, énfasis mío).

Peirce pone el acento no tanto en la similitud que tiene la imagen con lo real, sino en su origen genético a partir de esta, pero que necesita además de una suerte de triangulación con la percepción subjetiva. Así, la segunda mitad de la definición de Peirce alude a la causalidad y a la conexión dinámica, rasgos también presentes en la ontología de la imagen fotográfica tal y como la comprende Bazin. Esta coincidencia puede apreciarse en los dos sentidos expuestos por Peirce:

(1) Primero, en el vínculo genético o existencial entre objeto y fotografía, que aquí llamamos causalidad. Lo real es causa en un sentido cuasi-material de la existencia de la imagen fotográfica. Bazin habla de embalsamamiento o momificación, al igual que Barthes. Este último destaca también que el noema de la fotografía es "esto ha sido" (1994: 136). Esto implica procesos físico-naturales, como sucede también con el índice peirceano. Tanto la fotografía como los índices nos presentan un acto del pasado al que accedemos en un soporte distinto al que le dio origen. En el caso de la fotografía, a la misma apariencia del modelo, pero en un soporte analógico o digital; en el de la pisada, a través de la arena. En estos dos tipos de huella identificamos una conexión dinámica, pero de naturaleza distinta en cada caso.

(2) En segundo lugar, para reconocer el índice como tal es necesario que el sujeto conozca la relación entre el origen y el signo. Así, Jean-Marie Schaeffer señala a propósito del arché fotográfico que "una fotografía funciona como imagen indicial con la condición de que sepamos que se trata de una fotografía y lo que este hecho implica" (1990: 32). Es decir, no basta con el origen genético-físico, sino que necesita también de una interpretación por parte de la persona, en el sentido de una relación entre sus sentidos, su memoria y el modo en el que se lee en nuestro caso la imagen fotográfica como garantía de una realidad pasada. Al mirar una imagen fotográfica, el sujeto sabe que esta apunta hacia un objeto profílmico del 
pasado. El papel del sujeto, aquí, no es el de establecer un vínculo entre modelo e imagen fotográfica, sino el de reconocer esa relación causal. Aquí, Bazin también coincide con Peirce, quien defiende que "el índice está conectado físicamente con su objeto; hacen un par orgánico, pero la mente que lo interpreta no tiene nada que ver con esa conexión, excepto señalarla una vez establecida" (1994: 2.299).

Hasta aquí, el índice y la huella coinciden en contar ambos con una relación privilegiada con la realidad. Pero la huella baziniana rebasa los límites de la conexión dinámica, ya que para Bazin la imagen fotográfica no solo se relaciona con la realidad, sino que es la realidad, re-presentada en una nueva instancia que permite verla de otra forma. Será necesario atender a la primera parte de la definición de índice peirceano en vistas a establecer una distinción clara entre la huella de Bazin y el índice puro.

\subsection{Diferencias entre la huella baziniana y el índice puro de Peirce}

Cuando Peirce habla de índice, él mismo advierte de la dificultad de encontrar un índice puro, en el sentido de que los rasgos distintivos del indice son su falta de semejanza respecto del objeto que representa y que un indice se refiere a su referente de manera individual o singular, atrayendo la atención del que los percibe hacia dicho referente como una compulsión ciega (1994: 2.306). Peirce señala que los índices puros son difíciles de encontrar pues generalmente un tipo de signo implica otros, aunque de manera menos predominante, como es el caso de la huella en la arena: cuya forma recuerda la del pie, sin por ello tratarse de un icono de este. Cuando un signo comparte características con otros de la tricotomía peirceana, se llaman signos degenerados. Para alcanzar una comparación sistemática, será necesario estudiar la huella para diferenciarla del índice puro, tarea que acometeremos a continuación, y de los dos índices degenerados, el simbólico y el deíctico, cuyo estudio se realizará en el siguiente epígrafe.

Para medir la línea de confluencia entre Peirce y Bazin debemos 
considerar los tres aspectos a los que hace referencia en la primera parte de su definición de índice: la semejanza, la analogía y el que "esté asociado con caracteres generales que de hecho ese objeto posee". Dos de estos tres aspectos son matizables en la fotografía:

(1) La semejanza: una de las cualidades habitualmente reconocidas de la fotografía es el parecido entre el objeto fotografiado y su fotografía. Es decir, que el objeto se reconoce a través de la fotografía. Cuando Peirce define los índices puros, explica que estos:

pueden distinguirse de otros signos o representaciones por tres señales características: primera, que no tienen ninguna semejanza significante con sus objetos; segunda, que se refieren a individuos, a unidades singulares, a colecciones de unidades singulares, o a continuos singulares; tercera, que dirigen la atención a sus objetos por fuerza ciega [...]. Psicológicamente la acción de los indices depende de la asociación por contigüidad, y no de la asociación por semejanza o de operaciones intelectuales (1994: 2.306).

La semejanza no es un rasgo exclusivo de la fotografía, ni tampoco es una condición necesaria para que determinada imagen sea fotográfica. Bazin mismo decía que esta "puede ser borrosa, estar deformada, descolorida, no tener valor documental; sin embargo, procede siempre por su génesis de la ontología del modelo" (1966: 18-19). Del mismo modo, Barthes explica que en la fotografía importa más el tiempo (causalidad) que el objeto (semejanza): "en la fotografía el poder de autentificación prima sobre el poder de representación” (1994: 155). Sin embargo, a pesar de que la semejanza no es lo principal de la fotografía, es una propiedad que le suele venir aparejada y que permite, en definitiva, que encontremos ese punctum que nos afecta, en términos de Barthes; que se nos revele el mundo, diría Bazin. Si los objetos de la fotografía no fuesen reconocibles, probablemente su ontología se acercaría un poco más a cualquier otro signo 
indexical. Pero es esa semejanza lo que los hace únicos ante la mirada de los hombres y lo que les permite constituir representaciones realistas del mundo, puertas de acceso a la realidad. Mientras Peirce, que habla aquí de un índice puro, deja la semejanza en un segundo lugar, esta es inevitable en la fotografía, precisamente por sus particularidades genéticas. En este punto convendría recordar el analogon ex-machina al que refiere Luis, Alonso García, ya que es precisamente ese registro maquinal el que nos da, en palabras de Alonso, "un icono sobre un índice, un reflejo sobre una huella" (2010: 132). Gracias a ello, el sujeto puede apreciar aún los menores márgenes de semejanza, incluso en una fotografía borrosa o desgastada.

(2) La asociación a caracteres generales que posea el objeto. Los caracteres generales de los objetos son aquellos rasgos que los distinguen del resto de objetos, que los caracterizan: contorno, figura, color. Por ejemplo, la forma triangular de las copas de los pinos, que distingue a estos árboles de los sauces llorones, cuya copa es más parecida a un sombrero. La fotografía posee los caracteres generales de los objetos que representa precisamente en virtud de su producción causal. Barthes lo expresa de un modo muy claro cuando explica que "la fotografía reproduce mecánicamente lo que nunca más podrá repetirse existencialmente" (1994: 31). Y como guiño a Magritte, concluye que en una fotografía una pipa siempre es una pipa (1994: 33). Si nos atenemos a la definición y caracterización de la indexicalidad pura aportada por Peirce, constataremos que la fotografía no puede ser un índice genuino, porque la fotografía nos presenta con la imagen de un individuo y todo individuo posee determinados caracteres. La clave se encuentra en si la relación entre objeto y signo es existencial o no. Como explicó Peirce:

un Índice o Sema es un Representamen cuyo carácter Representativo consiste en que es un segundo individual. Si la Segundidad es una relación existencial, el Índice es genuino. Si la Segundidad es una referencia, el Índice es degenerado. Un Índice genuino y su Objeto deben ser individuos existentes (ya sean 
cosas o hechos), y su Interpretante inmediato debe ser del mismo carácter. Pero, ya que todo individuo debe tener caracteres, se sigue que un Índice genuino puede contener una Primeridad, y de este modo un Icono, como una parte constituyente de él. Todo individuo es un Índice degenerado de sus propios caracteres (1994: 2.283).

Tenemos aquí, entonces, dos formas de índice: uno que está existencialmente relacionado con su objeto (índice genuino) y uno que solo refiere a él (degenerado). Como en todo caso el índice lo es de un objeto, todo índice es una función segunda o segundidad. Pero como el mismo índice tiene sus caracteres propios, el índice puede considerarse un objeto en sí mismo, una primeridad: es segundo individual, pero individual primero en cuanto él mismo es un objeto. La fotografía, por su parte, sí guarda un vínculo existencial respecto al objeto que la origina y, sin embargo, también se lee como referencialidad debido a que es semejante al objeto. Esta explicación de Peirce y las peculiaridades de la fotografía como huella de luz nos permite sacar las siguientes conclusiones:

- Que el índice represente un segundo individual exige que no haya una relación de semejanza entre objeto y signo. La fotografía no sería un signo indexical puro, porque la imagen de la fotografía es idéntica a la imagen de la realidad que la causó.

- La segundidad de la fotografía sí posee un vínculo existencial con la realidad (causalidad), pero también se trata de una referencia, porque refiere al momento pasado en el que fue tomada esa fotografía.

- Como la primeridad se refleja a modo de espejo en la fotografía, esta cuenta también con un carácter icónico, a pesar de que su origen es causal, porque se reconoce una clara relación de semejanza respecto a la realidad que la origina.

- La afirmación peirceana de que todo individuo es un índice degenerado de sus propios caracteres puede aplicarse literalmente a la fotografia, 
cuya imagen es segundidad $y$ primeridad.

Podemos afirmar que la fotografía no es un índice puro, sino un subtipo del signo indexical: un índice degenerado. Debido a esto, toda lectura de "Ontologie" que pretenda dar cuenta de los planteamientos bazinianos desde la idea de indexicalidad pura corre el riesgo de caer en varios errores, desde la falsa identificación entre indexicalidad y realismo en la teoría de Bazin al polo opuesto, la negación de la necesidad de una causalidad en la génesis de la imagen para poder hablar de realismo cinematográfico.

\subsection{Similitudes entre la huella de luz y los índices degenerados}

En la clasificación de Peirce, encontramos dos tipos de índice degenerado: el índice icónico (index as a trace) y el índice simbólico o deíctico (deictic index). La fotografía es un índice icónico, pues su relación con la realidad representada es causal y de semejanza simultáneamente.

En cambio, el índice deíctico se llama simbólico precisamente por ser un híbrido entre el índice y el símbolo. Así, comparte con este último la arbitrariedad en su forma, como ocurre con las palabras "casa" o "mujer", que el sujeto identifica con determinada cosa o persona, pero varían en cada lengua pues se usan para designar la realidad gracias a un uso cultural y arbitrario. Peirce comprende que la naturaleza del índice deíctico establece un vínculo dinámico con el objeto porque su sentido nace del mismo, a pesar de la arbitrariedad de su construcción. Al nombrar un objeto mediante un índice deíctico, que en castellano podría ser el pronombre tuyo y en inglés yours, ambas palabras apuntan al mismo objeto y también adquieren su sentido en el mismo. De ahí la causalidad de su uso, la relación dinámica entre objeto y representación. Por ello, a diferencia de los símbolos puros, la indexicalidad simbólica se halla acotada a los pronombres, adverbios y expresiones que apuntan hacia una realidad existente a la par que cobran sentido gracias a la misma. Todas las 
culturas poseen estos índices deícticos, como "tú", "ahí", "hoy”.

Mary Ann Doane parte de la división entre huella y deixis para explicar que el cine siempre responde al primer subtipo de indexicalidad (el índice icónico) y no al segundo (el índice deíctico o simbólico) y explica que, aunque la indexicalidad no supone ninguna garantía de realismo, sí asegura el contacto real (contingente y contiguo ${ }^{7}$ ) entre objeto y representación, por lo que la imagen aumenta su credibilidad (2007a: 135-36).

Tras lo expuesto, es claro que el índice icónico de Peirce es semejante a la condición de huella que Bazin identifica en la fotografía, por la doble relación de causalidad y semejanza que guarda la fotografía con la realidad. En lo que sigue, se explorará directamente el concepto baziniano de huella para explicitar sus propias peculiaridades más allá de una aproximación semiótica.

\section{MÁS ALLÁ DEL ÍNDICE: EL CONCEPTO DE HUELLA EN BAZIN}

Tras exponer en qué consiste la indexicalidad desde la teoríabase de Peirce y su cercanía y limitaciones respecto a la comprensión baziniana de la fotografía como "huella de la realidad por medio de la luz" (Bazin, 1966: 17), en este epígrafe se ofrece al lector una caracterización de la huella fotográfica atendiendo a las cualidades descritas por Bazin en su obra. El concepto de huella surge del diálogo intelectual sobre el nuevo arte mantenido entre Bazin y sus coetáneos, y con una estrecha relación respecto de la tradición teórica francesa de principios de siglo. Figuras como Marcel L'Herbier, André Malraux o Jean-Paul Sartre son fundamentales para comprender esta noción. En este apartado se abordará

${ }^{7}$ Contingente porque las fotografías dependen de que otros objetos las causen mediante el registro. Y contigua porque, a diferencia de otros signos que se forman a partir del parecido o de operaciones mentales, para que se forme un índice-huella es necesario el contacto entre objeto y signo (2007b: 133). 
la labor de caracterizar la materia prima del cine mediante tres aspectos que influyen en su configuración: su génesis automática, su relación con el referente y su efecto en el espectador que la percibe.

\subsection{La génesis automática de la huella}

La fotografía es, en efecto, un tipo peculiar de huella, que vincula la ontología baziniana a la tradición teórica cinematográfica francesa de comienzos del siglo xx. Como advierte Mónica Dall'Asta, la "Ontologie" de Bazin evoca el concepto de fotogenia (photogénie) de Delluc y Epstein, que se encuentran a su vez en deuda con la teorización de la imagen realizada por Marcel L'Herbier (cfr. 2004: 86). Para L’Herbier, la cámara cinematográfica no es más que una máquina que imprime la vida (une machine à imprimir la vie) cuyo propósito es "transcribir tan fiel y verdaderamente como sea posible una determinada verdad fenoménica" (1918: 9). Sin duda, L’Herbier influyó profundamente en la concepción baziniana de la imagen fotográfica ya que, como podemos constatar en "Ontologie", Bazin se acoge a sus presupuestos para rebatir la teoría de André Malraux, quien consideraba la imagen fotográfica dentro de las artes plásticas. Malraux redactó su ensayo sobre cine desde un punto de vista histórico, proponiendo el cine como la culminación de la tarea que el arte barroco había emprendido años atrás: la tarea de lograr una más perfecta representación del mundo y por ende un mayor realismo (1959). Bazin responde a este planteamiento desmarcando el cine del cometido de la pintura de la siguiente manera:

el paso esencial de la pintura barroca a la fotografía no reside en un simple perfeccionamiento material (la fotografía continuará siendo durante mucho tiempo inferior a la pintura en la imitación de los colores), sino en un hecho psicológico: la satisfacción completa de nuestro deseo de semejanza por una reproducción mecánica de la que el hombre queda excluido. La solución no 
estaba tanto en el resultado como en la génesis (1966: 17).

Hablar de la imagen fotográfica como huella en la teoría de Bazin nos remite a su génesis; a ese momento concreto de su producción. Si la fotografía es capaz de propiciar un acceso a realidades fenoménicas, esto no se debe a los patrones de similitud espaciales, difiriendo así del planteamiento evolutivo de Malraux, quien inscribe la fotografía dentro del mismo cauce que el resto de artes plásticas. Bazin no habla de un linaje evolutivo - como el que emparentaba al Renacimiento con el Barroco-, sino de un salto evolutivo en el que surge un arte nuevo, una nueva especie. Del mismo modo, Bazin no se limita a hablar de la fotografía como representación, sino que destaca en ella su génesis, por la cual se sustrae un fragmento de realidad para re-presentarse a través de una huella de luz captada por la cámara. De ahí que, mientras Malraux habla de apariencias, Bazin centre su reflexión en el concepto de presencia. A continuación, se ofrece la argumentación de Bazin para distinguir a la imagen fotográfica del resto de imágenes:

La imagen fotográfica $-y$ singularmente la cinematográfica- ¿puede ser asimilada a las otras imágenes y, como ellas, distinguida de la existencia del objeto? La presencia se define naturalmente en relación al tiempo y al espacio. "Estar en presencia" de alguien es reconocer que es nuestro contemporáneo y constatar que se mantiene en la zona de acceso natural de nuestros sentidos (aquí, de la vista; en la radio, del oído). Hasta la aparición de la fotografía y más aún del cine, las artes plásticas, sobre todo el retrato, eran los únicos intermediarios posibles entre la presencia concreta y la ausencia. La justificación se centraba en el parecido, que excita la imaginación y ayuda a la memoria. Pero la fotografía es una cosa distinta. No es ya la imagen de un objeto o de un ser, sino 
su huella. Su génesis automática la distingue radicalmente de otras técnicas de reproducción. El fotógrafo procede, con la mediación del objetivo, a una verdadera captura de la huella luminosa: llega a realizar un molde (1966: 235).

Por su génesis causal, la imagen fotográfica es garantía de una realidad profílmica pasada. Por ello Schaeffer le llama "imagen del tiempo", un particular tipo de imagen que engloba "la indisolubilidad del espacio del icono y del tiempo del indicio" (1990: 48). De ahí que Bazin la comprenda como prueba de que lo que vemos existió u ocurrió realmente ante la cámara. Hasta aquí, la especificidad de la imagen fotográfica parece encontrarse en algún punto intermedio entre la teoría de la semejanza de Malraux y la indexicalidad peirceana. Sin embargo, el aspecto central de la huella baziniana está en el juego de relaciones que, gracias a su génesis automática, se establece entre ella, su referente real y el sujeto que la percibe.

\subsection{El referente de la imagen fotográfica}

El molde de luz descrito por Bazin actúa de un modo semejante al Sudario de Turín, donde se nos presenta una imagen negativa producida por la luminosidad del objeto. Si pensamos en otros tipos de molde, como es la técnica del vaciado, donde el objeto y sus reproducciones se producen gracias al contacto físico entre los materiales —algo similar al reflejo de luz que se posa sobre una base fotosensible, dejando su huella-, constatamos que el modelo de barro resultante es visualmente distinto del objeto original. Del mismo modo, una huella en la arena nunca lucirá como un pie, aunque lo recuerde. Por ello, al verla, nunca diremos "esto es un pie". En las fotografías, sin embargo, es distinto. En una fotografía de Pedro vemos a Pedro. O, mejor dicho, la fotografía nos re-presenta a Pedro sin importar su ausencia. En términos sartreanos diríamos que 
la imagen fotográfica actúa como un no-signo, como un analogon de la realidad (2006: 200) $)^{8}$.

La realidad de lo captado no es, sin embargo, una duplicación idéntica: ni Jean-Paul Sartre ni Bazin comprenden la fotografía como una sustitución del mundo9 . Esto llevará a Sartre a negar incluso que la fotografía sea un signo. El signo "está por" otra cosa, aunque sea cualitativamente distinta de su referente; la fotografía no es distinta de aquello a lo que remite, sino que es su imagen. Bazin tampoco comprende la fotografía como sustitución: "La existencia del objeto fotográfico participa [...] del modelo como una huella digital. Por ello se une realmente a la creación natural en lugar de sustituirla por otra distinta" (1966: 19).

Considerar la fotografía como no-signo o no-sustitución es solo una definición negativa en la que ambos están de acuerdo. Esto provee del marco común de base que permite a Bazin apropiarse del término ontología, usado originalmente por Sartre a propósito de la fotografía en L'Imaginaire. Pese a estas coincidencias entre ambos autores, al expresar en positivo lo que sí es la fotografía, constatamos que Sartre y Bazin no coinciden plenamente. Por un lado, Sartre piensa en la fotografía como un acto de conciencia, no una cosa. Para Sartre, "la imagen es conciencia de algo" (2006: 218). La imagen otorga un contenido representativo que remite a la realidad, como un signo directo, que rompe con la mediación. Para Sartre, la imagen fotográfica es pura intencionalidad, una realidad más cercana al acto de percibir un árbol que a un árbol en $\mathrm{s}^{10}{ }^{10}$. En cambio,

\footnotetext{
${ }^{8} \mathrm{Al}$ respecto, dice Sartre que "la imagen de mi amigo Pedro no es una vaga fosforescencia, una huella dejada en mi conciencia por la percepción de Pedro; es una forma de conciencia organizada que se refiere, a su manera, a mi amigo Pedro, es una de las maneras posibles de apuntar al ser real de Pedro" (2006: 200).

${ }^{9}$ Muchos otros filósofos de la época tampoco consideraban la fotografía como duplicación. Así lo recoge Brian Price en su artículo "Heidegger and Cinema", donde Prince explica que para Heidegger "the work of cinema is not to supplant the world. I'm sure that's even possible. Rather, it organizes the world" (2009: 119).

${ }^{10}$ Sartre comprende el signo en los términos en que lo expresa Umberto Eco, cuando dice que "signo es cualquier cosa que pueda considerarse como substitutivo significante de cualquier otra cosa" (1977: 31). Para Sartre, las fotografías no sustituyen, sino que resti-
} 
Bazin destaca en su "Ontologie" que la fotografía nos afecta como un fenómeno natural, como una flor o un copo de nieve. No solo en un sentido figurado, sino real. Para Sartre, la fotografía elimina la mediación y la sustituye por su pura idealidad; para Bazin, en cambio, la fotografía no niega toda mediación, sino que precisamente se resuelve en ella. Mientras para Sartre la fotografía nos permite percibir un árbol (acto de conciencia) sin que haya un verdadero árbol delante (cosa), para Bazin, el árbol está ahí, re-presentado de verdad.

En este sentido, las imágenes fotográficas representan un dilema especial porque son realidades físicas que, sin embargo, remiten a otras realidades físicas. Es decir, son un objeto cuya consistencia se fija precisamente en remitir a otro objeto. De este modo, podemos matizar la defensa sartreana del no-signo al decir que la naturaleza de la imagen de registro es, más bien, dual. Esta dualidad se debe a que del mismo modo que la fotografía puede leerse como un signo (objeto que remite a un objeto distinto que le dio origen, como el humo al fuego), no se limita a señalar más allá de sí mismo, sino que se refiere a lo que la propia imagen constituye (la imagen de algo o, mejor, un algo). Así, la huella fotográfica no solo es distinta de otras huellas, sino también de otras imágenes — pictóricas o escultóricas - cuya existencia se reduce a la representación ${ }^{11}$, es decir, a la referencia a realidades autónomas.

Así, la imagen fotográfica no debe ser comprendida como una duplicación del modelo, sino como una huella particular que nos devuelve el momento concreto de la cosa representada, cuya contigüidad ha quedado en el pasado y, sin embargo, al haber sido sustraída fotográficamente

\footnotetext{
tuyen una realidad previa que participó de su origen (2006: 218).

${ }^{11}$ En este sentido, la imagen más cercana a la fotografía sería el icono bizantino, cuya veneración se debe a que constituye una especie de vehículo entre el prototipo y su representación mediante la imitación de una forma determinada (Weitzmann, 1978: 7-23). Sin embargo, la fotografía supera también a este tipo de representaciones en términos de presencia; ya que la presencia propia de los iconos bizantinos no resulta de una génesis automática-causal, sino del cumplimiento de una serie de normas establecidas por la tradición.
} 
del cauce general del tiempo, nos es presentada realmente. Este rasgo distintivo de la fotografía es lo que la acerca más al índice icónico que al índice puro o que al índice deíctico descritos por Peirce. Y, al mismo tiempo, es lo que la distingue de todo tipo de signo, sea artificial o natural, acercándose más a ser una manifestación del referente que un sustituto. Y de ahí que este artículo proponga desembarazar el realismo baziniano de exigencias impuestas por la indexicalidad. Porque la condición de huella —o causalidad - es parte fundamental de la ontología de la imagen fotográfica $\mathrm{y}$, sin embargo, su naturaleza se desmarca de otros signos, incluso indexicales. La imagen fotográfica está en un ámbito intermedio entre la existencia real y la representación.

\subsection{El coeficiente de realismo en la huella baziniana}

Las lecturas que reducen la ontología baziniana a la indexicalidad y que consideran que Bazin confiere - en virtud exclusiva de dicha condición de índice - un realismo inherente a la imagen cinematográfica, hacen una doble simplificación. La primera es la ya descrita anteriormente de equiparar ontología fotográfica e indexicalidad como sinónimos. Y la segunda consiste en considerar que Bazin comprende el realismo del cine como un derivado automático de la ontología de su material. Por eso es necesario aclarar también que, para Bazin, la ontología de la imagen fotográfica es una condición necesaria, pero no suficiente, para alcanzar el realismo cinematográfico. En este punto conviene tener en mente la distinción que hace González Requena entre lo fotográfico (la imagen fotográfica en sí, donde participa lo azaroso, la huella y lo que es de orden no simbólico) y la fotografía (la utilización de lo fotográfico con finalidades discursivas). Lo radical fotográfico, diría González Requena, "es lo que en la fotografía escapa tanto al orden semiótico como al orden imaginario: lo que hace de ella huella real de lo real. Lo radical fotográfico es, en suma, lo Real en la fotografía" (2013. Énfasis mío) ${ }^{12}$. Bazin parece apuntar

${ }^{12}$ Esta misma distinción también está presente en "El mensaje fotográfico", de Barthes 
precisamente a esto cuando explica que, si bien la imagen fotográfica no es realista per se, sí aporta un coeficiente de realismo que no está presente en la materia prima de otras artes:

Todo lo que ocurre en la pantalla posee un coeficiente de realismo al que el resto de artes figurativas no podrían aspirar. Percibimos esas imágenes como un calco del mundo exterior; éstas existen como cuando un objeto que se refleja en un espejo (1953: 14-16).

El coeficiente de realismo de la imagen cinematográfica está relacionado con el poder irracional de la fotografía, que nos persuade para creer en ella. Diría Bazin que la génesis automática de la imagen de registro:

ha trastocado radicalmente la psicología de la imagen. La objetividad fotográfica le da una potencia de credibilidad ausente de toda obra pictórica. Sean cuales fueren las objeciones de nuestro espíritu crítico nos vemos obligados a creer en la existencia del objeto representado, re-presentado efectivamente, es decir, hecho presente en el tiempo y en el espacio (1966: 1516).

Esta capacidad del cine y de la fotografía descrita por Bazin como un efecto en la psicología del sujeto es denominada por Tom Gunning con el término pretensión de verdad (truth claim) (2004: 41). La pretensión de verdad, explica Gunning, no es una propiedad inherente a la fotografía, sino un poder que le confiere el sujeto al contemplarla. Gunning comprende que dicha pretensión de verdad se fundamenta sobre dos pilares que se establecen como las dos únicas alternativas para el realismo fotográfico: una basada en el vínculo existencial entre imagen y modelo (indexicality) 
$y$ la segunda basada en el parecido (accuracy) (2004: 41-43). Sin embargo, el realismo que posee la imagen fotográfica, según Bazin, no se agota ni se identifica con ninguno de estos dos rasgos, al menos no en exclusiva. A continuación, se dará cuenta de ambos pilares en la definición de Gunning para cerrar nuestra argumentación sobre el realismo baziniano desde la perspectiva del sujeto que percibe la imagen fotográfica y el alcance de su efecto realista en el mismo.

\subsubsection{La indeterminación de la imagen causal}

A menudo se tiende a comprender la corriente realista del cine como una teoría esencialista. Esto es, como si la fotografía y el cine adquirieran un realismo definitivo por el simple hecho de existir. En esta línea, Martin Seel y Mary Ann Doane buscan una tercera vía que se conoce como tesis indeterminista del cine (en oposición a la tesis realista, la anti-realista y la ilusionista (cf. Seel, 2008). Doane explica que, si bien la indexicalidad de las fotografías refiere a la realidad, eso no implica que la imagen alcance el realismo de forma vinculante, y ejemplifica esta afirmación aludiendo a las fotografías abstractas (2007a: 4). Efectivamente, una fotografía abstracta refiere a la realidad y no presenta una representación realista del mundo. Sin embargo, aún en este tipo de fotografías, lo que presenciamos es el mundo concreto que nos rodea y no una creación independiente de nuestro mundo físico, como puede ocurrir en los dibujos o la pintura. Por eso, la ontología de la imagen fotográfica, en la teoría baziniana, posee un papel central. Ya que es en virtud de la ontología de sus imágenes que el cine es de tendencia realista.

Sobre este primer aspecto señalado por Gunning, que vincula la pretensión de verdad con la indexicalidad de la imagen, cabe añadir que, al hablar de realismo, Bazin se refería a algo más allá de la representación: a la posibilidad que presenta la imagen cinematográfica para acceder a la realidad de un modo análogo a nuestra percepción en el mundo físico. Como explica Seel, la fotografía es un medio completamente realista, 
cuya apariencia garantiza ser un indicador de que algo estuvo realmente frente a la cámara $\mathrm{y}$, al mismo tiempo, es un medio indiferente tanto hacia el realismo como al anti-realismo (2008: 170). Seel defiende que la fotografía no implica necesariamente el realismo de lo representado pues este depende del uso creativo que el autor haga de la misma-, pero sí es garantía del registro.

Este último matiz sobre la indeterminación de la fotografía (y del cine) se desarrolla en consonancia con la teoría de Bazin. De mano de Seel puede afirmarse que "la imagen fotográfica se caracteriza por una disposición realista que puede o no ser satisfecha. Esta contiene la promesa de ser indicadora de un presente que ha pasado" (2008: 172). Aunque Seel aplica esta "posibilidad privilegiada" para lograr una representación realista tan solo a la fotografía, su argumento se puede aplicar del mismo modo al cine en el contexto de la teoría de Bazin. Porque, como se ha dicho, la ontología de la imagen fotográfica para Bazin supone una condición de posibilidad de la representación realista. $\mathrm{Y}$ es una condición privilegiada respecto a la de otras artes cuya fase de producción es siempre mediada por la subjetividad del artista (la pintura, la escultura). No es que la ontología exija o satisfaga, de una vez y por todas, el realismo de la representación. La ontología de la imagen fotográfica supone tan solo un primer paso en la posibilidad del realismo: el registro de la realidad (que 1leva aparejada, como novedad respecto a las demás artes, una veracidad automáticamente capturada). En el caso de la imagen cinematográfica, esta incluye dentro de sí, además, la posibilidad de restituir el tiempo.

Que Bazin parta de la ontología para proponer que el cine es realista por excelencia es una afirmación entusiasta que se desprende de las posibilidades del medio. Sin embargo, al igual que Doane y Seel, Bazin era consciente de que este coeficiente de realismo podía o no aprovecharse en este sentido. 


\subsubsection{La semejanza y el realismo}

El segundo aspecto discutido por Gunning en su artículo tiene que ver con la semejanza. Gunning propone que para el realismo cinematográfico basta con que la imagen nos permita creer en ella, sin importar si su origen está en la apariencia del mundo (imagen de registro) o si es fruto de la creatividad de un animador (CGI). Gunning defiende que lo importante en el realismo de un filme es la verosimilitud, el fotorrealismo de la imagen ${ }^{13}$. Sin embargo, se podría refutar a Gunning diciendo que el cine de animación fotorrealista no imita el mundo, sino al cine (de registro) mismo, porque no busca necesariamente una representación fiel del mundo, sino alcanzar la capacidad de emular ese poder irracional que la fotografía despierta en nosotros y nos hace creer en lo representado.

Llegados a este punto, resulta pertinente recordar que, al abordar la relación entre la ontología de la imagen fotográfica y el realismo, Bazin distingue entre dos tendencias diferentes que confluyen en la pintura antes de la invención de la fotografía. Bazin explica que, a partir de la invención de la perspectiva:

la pintura se encontró dividida entre dos aspiraciones: una propiamente estética - la expresión de realidades espirituales donde el modelo queda trascendido por el simbolismo de las formas-y otra que no es más que un deseo totalmente psicológico de reemplazar el mundo exterior por su doble (1966: $15)$.

Bazin señala la invención de la perspectiva como algo análogo al pecado original en el Antiguo Testamento: la caída (1966: 16). Porque, a consecuencia de la introducción de la perspectiva en las artes plásticas,

\footnotetext{
${ }^{13}$ En trabajos posteriores, Gunning ampliará sus reflexiones hasta identificar su comprensión del realismo cinematográfico con un supuesto idealismo baziniano (Gunning, 2007, 2010).
} 
explica Bazin, el artista relegó a un segundo plano la expresión de realidades espirituales para centrarse en alcanzar una semejanza cada vez mayor entre su obra y la realidad física. Es decir, condenó a la pintura a esforzarse por alcanzar un parecido superficial en lugar de potenciar la exploración de la condición humana, que es lo propio del arte.

Por ello decía Bazin que la invención de fotografía redimió a las artes plásticas de su obsesión realista. La originalidad de la fotografía radica en que, gracias a su doble naturaleza, la semejanza fotográfica respecto del modelo no solo parece sino que garantiza la existencia pasada del objeto fotografiado. Es decir, el cine representa y revela simultáneamente el mundo: "Las categorías de la semejanza que especifican la imagen fotográfica determinan también su estética con relación a la pintura. Las virtualidades estéticas de la fotografía residen en su poder de revelarnos lo real" (1966: 19). Es decir, la imagen fotográfica no es una imagen que busca representar el mundo sino la realidad misma, que se nos re-presenta en su propia imagen.

\section{CONCLUSIONES}

Las mismas teorías que reforzaron la identificación entre la comprensión baziniana de la huella fotográfica y la indexicalidad peirceana evidencian las principales diferencias entre la perspectiva semiótica y la particular lectura de André Bazin. En términos generales, estas consisten en la función que las imágenes cumplen en relación al mundo físico. Mientras para autores de impronta semiológica la imagen fotográfica actúa como un sustituto del mundo, desde la perspectiva realista baziniana dichas imágenes constituyen un punto de acceso privilegiado hacia la realidad.

Este punto de partida epistemológico puede constatarse, a su vez, en los resultados que arroja la comparación entre el índice puro y la huella de luz que caracteriza la imagen fotográfica. La principal diferencia entre ambas radica en que la fotografía, además de provenir de una génesis causal, es semejante al objeto que la origina. En este sentido, la 
fotografía podría ser considerada como un índice icónico que, siguiendo la terminología peirceana, sería un índice degenerado. Pero la indexicalidad icónica tampoco agota ni define la imagen fotográfica. En el planteamiento baziniano, que se realiza temporal e intelectualmente al margen de la semiótica, es posible identificar diversas influencias intelectuales con las que el teórico francés entra en diálogo y que resultan fundamentales en su caracterización de la huella fotográfica, especialmente las de Marcel L’Herbier, André Malraux y Jean-Paul Sartre. Es, quizá gracias a esta variedad de enfoques, que en el marco del pensamiento baziniano la imagen fotográfica se debate entre la presencia propia de los objetos cotidianos y la ausencia propia de una imagen que carece de cuerpo. En este sentido, Bazin coincide con Sartre cuando afirma que la imagen fotográfica no reemplaza ni duplica, sino que restituye la realidad fotografiada, aunque sustrayéndola del cauce temporal para inmortalizarla.

Ese proceso exclusivo de las imágenes de registro propicia, según el autor, una tendencia realista en la representación cinematográfica. La imagen-huella, sirve como evidencia del mundo, aportando un coeficiente de realismo a la imagen que nos hace creer en ella. Aun sabiendo que se trata de una representación, no podemos dudar de la existencia previa del objeto representado, que actúa como un espejo diferido de la realidad. Esta cualidad de su materia prima predispone al cine, según Bazin, a ser un arte esencialmente realista. Sin embargo, esta tendencia no necesariamente se ve cumplida, porque dependerá del uso que el artista haga de las imágenes para que el producto resultante cumpla o no con esta tendencia genética. 


\section{REFERENCIAS BIBLIOGRÁFICAS}

ALONSO GARCÍA, L. (2010). Lenguaje del cine, praxis del filme: una introducción al cinematógrafo. México: Plaza y Valdés.

BARTHES, R. (1961). "Le message photographique". Communications 1, 127-138 (también en https://doi.org/10.3406/comm.1961.921 [01/06/2018]).

(1964a). "Réthorique de l'image". Communications 4, 40-51 (también en https://doi.org/10.3406/comm.1964.1027 [01/06/2018]).

(1964b). "Éléments de sémiologie". Communications 4, 91-

135 (también en https://doi.org/10.3406/comm.1964.1029 [01/06/2018]).

(1994). La cámara lúcida: nota sobre la fotografía, Sala-Sanahuja (trad.). Barcelona: Paidós.

BAZIN, A. (1953). "Le langage de notre temps". En Regards neufs sur le cinéma, Jacques Chevalier (ed.), 14-16. París: Le Seuil.

(1966). ¿Qué es el cine? Madrid: Rialp.

DALL'ASTA, M. (2004). “Thinking about Cinema: First Waves". En The French Cinema Book, Temple y Witt (eds.), 82-90. Londres: Palgrave BFI.

DOANE, M. A. (2007a). "Indexicality: Trace and Sign: Introduction". Differences: A Journal of Feminist Cultural Studies 18.1, 1-6 (también en https://doi.org/10.1215/10407391-2006-020 [20/11/2017]).

(2007b). "The indexical and the concept of medium specificity". Differences: A Journal of Feminist Cultural Studies 18.1, 128152 (también en https://doi.org/10.1215/10407391-2006-025 [20/11/2017]).

(2012). La emergencia del tiempo cinemático: la modernidad, la contingencia y el archivo. Murcia: Cendeac.

ECO, U. (1974). La estructura ausente. Barcelona: Lumen. 
(1977). Tratado de semiótica general. Barcelona: Lumen.

GRIMER, P. (2007). "Image as Trace: Speculations About an Undead Paradigm". Differences: A Journal of Feminist Cultural Studies 18.1, 7-28.

GONZÁLEZ REQUENA, J. (2013). “La imagen y la realidad. Los registros de la imagen". Memoria de Cátedra. El ser de las imágenes. De la Teoría al Análisis de la Imagen. Madrid: Universidad Complutense (también disponible en http://gonzalezrequena.com/textos-enlinea-0-2/libros-en-linea/el-ser-de-las-imagenes/volumen-i-laimagen-y-la-realidad-los-registros-de-la-imagen-b/[31/05/2018]).

GUNNING, T. (2004). "What's the Point of an Index? or, Faking Photographs". NORDICOM 25, 1/2, 39-49.

(2007). "Moving Away from the Index: Cinema and the Impression of Reality”. Differences: A Journal of Feminist Cultural Studies 18.1, 29-52.

(2010). "The World in Its Own Image: The Myth of Total Cinema". En Opening Bazin: Postwar Film Theory and Its Afterlife, Joubert-Laurencin y Andrew (eds.), 119-127. Nueva York: Oxford University Press.

L'HERBIER, M. (1918). "Hermès et le silence". Le Film 29, 110111, 712 (también disponible en https://www.film.uzh.ch/dam/ jcr:b95537a2-623a-4db8-846c-b701ce26c22c/L'Herbier_1918_ Herm\%C3\%A8s_et_le_silence_Original.pdf [15/12/2017]).

LEBEDEV, O. (2016). “'La robe sans couture de la réalité': André Bazin et l'apologie du réalisme cinématographique". Bulletin d'analyse phénoménologique XII 4.9, 189-209 (también en https://popups. uliege.be:443/1782-2041/index.php?id=870 [20/11/2017]).

LEFEBVRE, M. \& FURSTENAU, M. (2002). "Digital Editing and Montage: The Vanishing Celluloid and Beyond”. Cinémas: Revue d'études cinématographiques 13, 1-2, 69-107 (también en http:// id.erudit.org/iderudit/007957ar [25/10/2017]).

MALRAUX, A. (1959). Psicología del cine seguido de El hombre y la 
cultura artística. Buenos Aires: J.I.

PEIRCE, Ch. S. (1994). The Collected Papers of Charles Sanders Peirce (también en http://www.unav.es/gep/Peirce-esp.html [25/10/2017]).

PRICE, B. (2009). "Heidegger and Cinema". En European Film Theory, Trifonova (ed.), 108-112. Nueva York: Routledge.

RIFKIN, S. J. (2012). “André Bazin's 'Ontology of the Photographic Image: Representation, Desire, and Presence"'. Dissertation Abstracts International, Section A: The Humanities and Social Sciences. Ottawa: Carleton University.

SARTRE, J.-P. (2006). La imaginación. Barcelona: Edhasa.

SEEL, M. (2008) "Realism and Anti-Realism in Film Theory". Critical Horizons. Routledge 9.2, 157-175 (doi: 10.1558/crit.v9i2.157 [15/12/2017]).

SCHAEFFER, J-M. (1990). La imagen precaria: del dispositivo fotográfico. Madrid: Cátedra.

SONTAG, S. (1978). On photography. Nueva York: Farrar, Straus and Giroux.

WATTS, P.; ANDREW, D.; CITTON, Y.; DEBAENE, V.; IORIO, S. D. \& BARTHES, R. (2016). Roland Barthes' Cinema. Nueva York: Oxford University Press.

WEITZMANN, K. (1978). The Icon: Holy Images, Sixth to Fourteenth Century. Londres: Chatto and Windus.

WOLLEN, P. (1970). Signs and meaning in the cinema. Londres: Thames and Hudson.

Recibido el 20 de febrero de 2018.

Aceptado el 27 de junio de 2018. 